\title{
Intravascular ultrasound-guided lithotripsy in a calcified saphenous vein graft
}

\author{
Sylwia Iwańczyk, Włodzimierz Skorupski, Aneta Klotzka, Patrycja Woźniak, Marek Grygier, Maciej Lesiak
}

$1^{\text {st }}$ Department of Cardiology, Poznan University of Medical Sciences, Poznań, Poland

Correspondence to: Sylwia Iwańczyk, MD, $1^{\text {st }}$ Department of Cardiology, Poznan University of Medical Sciences,

Długa 1/2, 61-848 Poznań, Poland,

phone: +486185492 22, e-mail: syl.iwanczyk@gmail.com

Copyright by the Author(s), 2021

Kardiol Pol. 2021;

79 (11): 1290-1291;

DOI: 10.33963/KP.a2021.0106

Received:

August 22, 2021

Revision accepted:

September 7, 2021

Published online:

September 8, 2021
Percutaneous coronary interventions (PCIs) in saphenous vein grafts (SVGs) can present many challenges and are associated with a high incidence of stent failure [1]. Therefore, optimal preparation of the lesion and optimization of the $\mathrm{PCl}$ procedure are crucial for the long-term prognosis. Morphologically, SVG atherosclerosis tends to be diffuse and concentric, with the softer, friable, larger plaque and little evidence of calcification. However, uniquely, the degeneration processes of the vein graft can also include severe calcification [2]. We present a case in which a non-dilatable, calcified SVG was successfully treated by Shockwave Intravascular Lithotripsy (S-IVL).

A 68-year-old woman with hypertension, hyperlipidemia, past medical history of coronary artery bypass graft (CABG), and $\mathrm{PCl}$ of the right coronary artery (RCA) due to vein graft occlusion, was admitted to our hospital due to unstable angina. Coronary angiography revealed critical stenoses in proximal, medial, and distal segments of SVG supplying the left anterior descending artery (LAD) (Figure 1A). In addition, there was significant stenosis in the left main (LM) and the left circumflex ar-
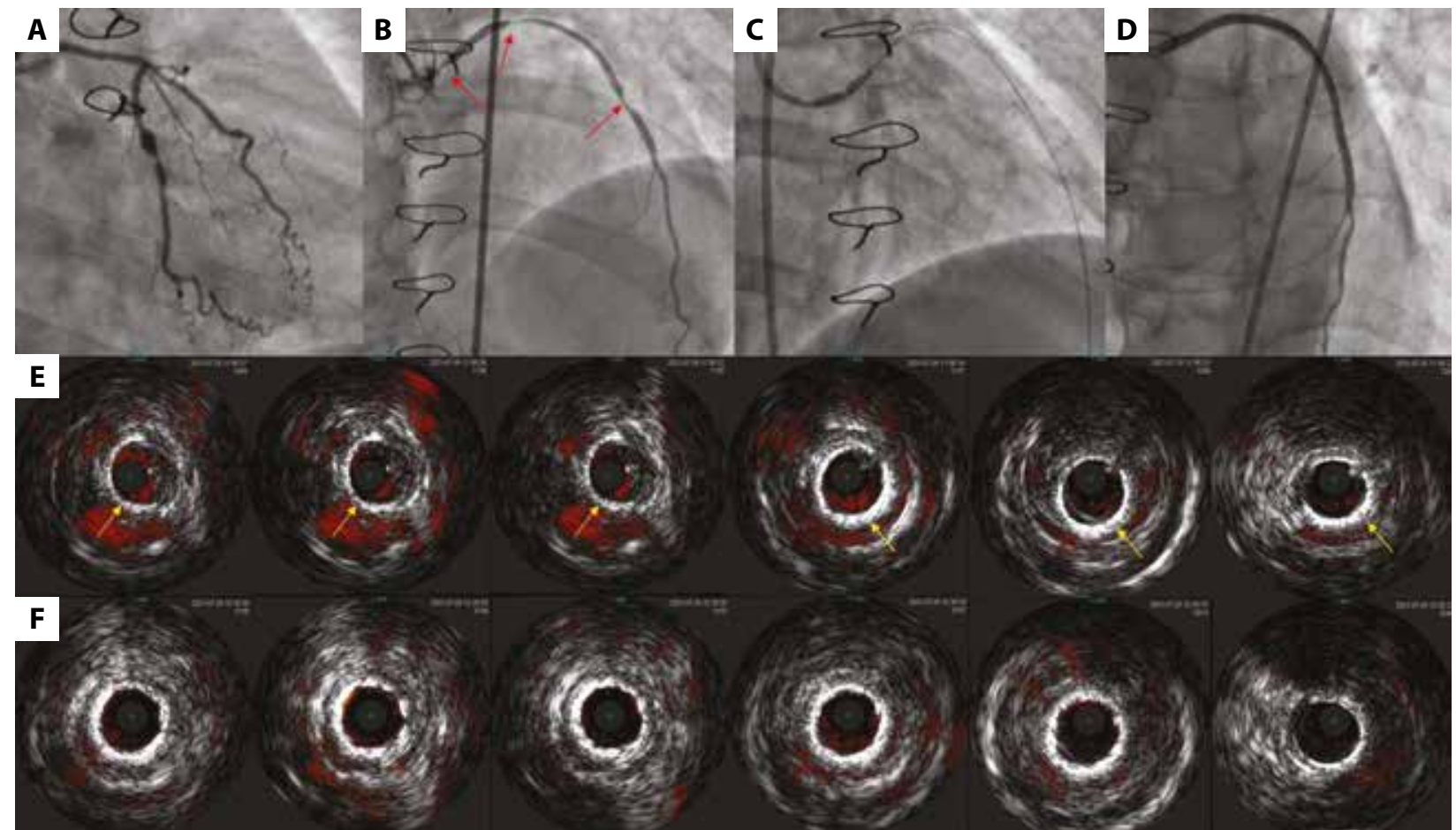

Figure 1. A. An anteriorposterior caudal angiographic view of the left coronary artery: significant stenosis of the left main and left circumflex artery (LCX). B. Saphenous vein graft (SVG) to the left anterior descending artery: significant stenosis of proximal, medial, and distal segments (red arrow). C. Non-compliant balloon underexpansion in the proximal segment of SVG. D. Intravascular ultrasound (IVUS) cross-sections of the proximal SVG after SIVL and stent implantation. E. Intravascular ultrasound (IVUS) cross-sections of the proximal SVG before shockwave intravascular lithotripsy (SIVL), calcium rings are marked with the yellow arrow. F. Final angiographic view of SVG 
tery $(\mathrm{LCX})$ (Figure 1B). At the first stage of $\mathrm{PCl}$, we decided to treat the bypass graft to the LAD. A pre-dilatation with a $2.5 \times 15 \mathrm{~mm}$ non-compliant (NC) balloon was successfully performed in the middle and distal segments, followed by stenting with Ultimaster $3.0 \times 24 \mathrm{~mm}$ and Ultimaster $2.5 \times 15 \mathrm{~mm}$, respectively. The proximal lesion was pre-dilated with a $3.0 \times 15 \mathrm{~mm} \mathrm{NC}$ balloon; however, it did not expand (Figure 1C). Intravascular ultrasound (IVUS) showed an extensive calcification in the proximal segment of SVG (Figure 1D). Therefore, we decided to use a $3.0 \times 12 \mathrm{~mm}$ S-IVL balloon. In total, there were 80 applications (at $4 \mathrm{~atm}$ ) delivered in the proximal vein graft, resulting in an optimal expansion of the S-IVL balloon at 6 atm. Subsequently, we successfully implanted a drug-eluting Ultimaster $3.0 \times 18 \mathrm{~mm}$ stent (Figure 1E). The optimal effect of the procedure was confirmed by IVUS (Figure 1F).

Percutaneous coronary intervention in SVG differs significantly from $\mathrm{PCl}$ in a diseased native coronary artery. Although a severe SVG calcification is rare, its presence can lead to incomplete expansion of stents and, consequently, a higher incidence of stent failure. S-IVL appears to be a safe, effective, and feasible strategy for calcium modification in native coronary arteries $[3,4]$. We demonstrated intravascular lithotripsy as a safe and effective treatment method of a calcified SVG disease as well.

\section{Article information}

Conflict of interests: None declared.

Open access: This article is available in open access under Creative Common Attribution-Non-Commercial-No Derivatives 4.0 International (CC BY-NC-ND 4.0) license, allowing to download articles and share them with others as long as they credit the authors and the publisher, but without permission to change them in any way or use them commercially. For commercial use, please contact the journal office at kardiologiapolska@ptkardio.pl.

How to cite: Iwańczyk S, Skorupski W, Klotzka A, et al. Intravascular ultrasound-guided lithotripsy in a calcified saphenous vein graft. Kardiol Pol. 2021; 79(11): 1290-1291, doi: 10.33963/KP.a2021.0106.

\section{REFERENCES}

1. Russo F, Chieffo A, Carlino M, et al. Intravascular ultrasound-guided coronary lithotripsy treatment of in-stent restenosis in saphenous venous graft. J Invasive Cardiol 2021;33(2): E141-E142.Indexed in Pubmed: 33531446.

2. Harskamp RE, Lopes RD, Baisden CE, et al. Saphenous vein graft failure after coronary artery bypass surgery: pathophysiology, management, and future directions. Ann Surg. 2013; 257(5): 824-833, doi: 10.1097/SLA.0b013e318288c38d, indexed in Pubmed: 23574989.

3. Iwańczyk S, Włodarczak A, Hiczkiewicz J, et al. Feasibility of intravascular lithotripsy for calcific coronary lesions: A multi-institutional experience. Catheter Cardiovasc Interv. 2021; 98(4): E540-E547, doi: 10.1002/ccd.29792, indexed in Pubmed: 34051136.

4. Iwańczyk S, Siniawski A, Panowicz M, et al. Successful intravascular lithotripsy for covered stent underexpansion due to severely calcified plaque. Kardiol Pol. 2020; 78(3): 247-248, doi: 10.33963/KP.15119, indexed in Pubmed: 31916543. 